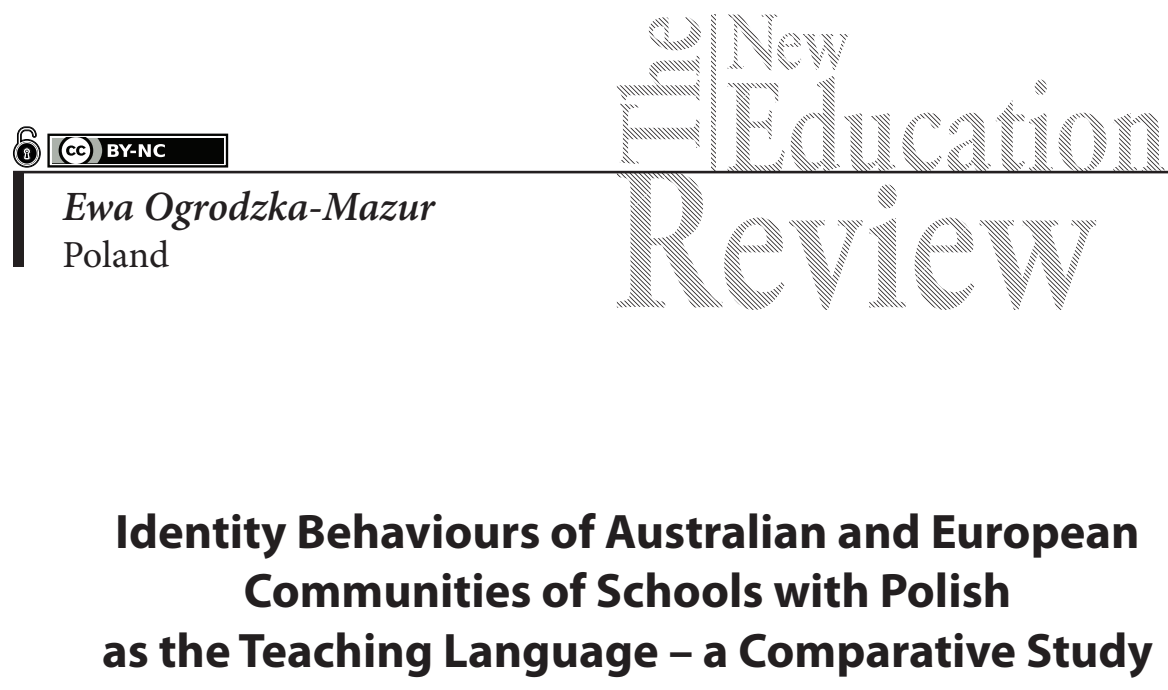

DOI: 10.15804/tner.2018.54.4.02

\begin{abstract}
The study comprises the presentation of an authorial approach to cultural identity, viewed from the perspective of the communities (consisting of children, parents and teachers) of schools with Polish as the teaching language in Australia and some selected European countries (Austria, France, the Czech Republic). In reference to the culturalistic model of identity, the characteristics of the most frequent identity behaviours of these communities were provided in the ethnic, national, integrative and mixed dimension. The author also indicates the contemporary contexts of identity shaping, which are determined by migration processes and multiculturalism. By formulating the most important conclusions resulting from the research, the need is indicated for implementing intercultural education in schools with Polish as the teaching language. Among other things, this will enhance the shaping of a multidimensional feeling of identity.
\end{abstract}

Keywords: identity, feeling of identity, identity behaviours, schools with Polish as the teaching language, comparative study

\title{
Introduction
}

In Polish pedagogy, there are not many studies of social, cultural and educational functioning of children in culturally diversified environments. The current knowledge in this field, presented mostly within comparative pedagogy, most fre- 
quently consists in presenting expert opinions on the situation of school education of majority and/or minority groups in particular countries as well as the applied solutions. Some significant works in this field (e.g., Lewowicki, Nikitorowicz, Szczurek-Boruta, 2010) concern school education and sociocultural phenomena taking place in Polish borderlands, most often described in reference to children and youth.

Viewing the educational situation of Polish learners, their parents and teachers from the social, the cultural and pedagogical perspective of Australia and selected European countries provides the opportunity to capture the differences and similarities in the ways of implementing intercultural education (or its lack). Such a type of research is inevitably associated with the reflection upon the way in which contemporary humanity understands cultural dimensions, their role in human life and the extent to which they shape individual and social cultural identity.

Schools educating in Polish function in Europe and in the world within educational systems of other countries. These countries have different history, experiences, conditions of life and dominating patterns of social functioning. This largely determines the perception and comprehension of various identity fields and the related behaviour patterns.

\section{The theoretical and methodological assumptions of the research}

What was applied in the pedagogical analysis of children's education in Polish schools abroad were the theoretical conceptualizations, referring to Jerzy Nikitorowicz's (1) concept of intercultural education (2009, pp. 282-296), Paweł Boski’s (2) cultural model of acquiring biculturalism and his (3) concept of cultural distance (1995, pp. 143-162).

What has become an important perspective in the search for regularities ruling the shaping of the feeling of identity in changing conditions of cultural diversity is Tadeusz Lewowicki's (4) theory of identity behaviours. All the six fields (elements) of identity distinguished here are important determinants of identity behaviours (Lewowicki, 2018, pp. 191-205).

Both qualitative and quantitative methods were used in the research procedure -ethnographic observation, individual narrative interviews with children, questionnaire studies among teachers and parents and document analysis.

The studies were conducted over the period 2012-2017 in schools educating in Polish in Australia (Perth) and some selected European countries (Austria Vienna; France - Paris; the Czech Republic - Prague, Czech Cieszyn). The research 
involved 509 learners - 318 (62.5\%) from primary school (138 from lower and 180 from higher grades) and 191 (37.5\%) from lower-secondary schools - grades 1-3.

204 parents participated in the studies $-126(62 \%)$ parents of primary school learners and 78 (38\%) of lower-secondary school learners. In many cases, the parents answered the questionnaires jointly, which provided data concerning, e.g., education and mixed marriages (from 319 participants) or the length of their stay abroad (from 345 respondents).

The group of teachers was the smallest and consisted of 19 respondents. This is an effect of a small number of teachers working in schools with Polish as the teaching language and of the tendency to treat participation in studies with unwillingness, which can be noticed in the case of both teachers and school head teachers.

\section{Identity behaviours of the communities of schools educating in Polish - research results}

The functioning of children, their parents and teachers from Polish schools abroad is associated with the natural feeling of belonging to a particular social group (including the national or cultural one of the country of residence) and enables self-identification, which is the basis for differentiating between Me-Us and Others-Them. Formed at many differently ordered platforms, the outer (attributing the identity) and/or inner (self-identifying) character of identification shapes the feeling of identity.

What was applied in individual talks and questionnaires was a scale measuring self-assessment in the field of national identification. The scale assumes that both children and parents might experience various intensity of the feeling of identity, which involves: weak identity (Polish identity is weaker than Australian/Austrian/ Czech/French or the opposite), mixed balanced identity (no dominating identity feeling both a Pole and an Australian/Austrian/Czech/French) and a strong feeling of identity (domination of one homogeneous Polish/Australian/Austrian/Czech/ French identity), which reflects the identification-alienation behaviour patterns.

\section{Children}

The examined children from the grades (cf., Figure 1) declare different intensity levels of their feeling of identity, which is determined by the environment of the 
country of their permanent or temporary residence, their age and the length of stay abroad. 55\% of the children from Australia and over a half of the learners living in Austria (59\%), France (71\%) and the Czech Republic in Prague (77\%) manifest Polish identity, the intensity of which increases with age. The respondents' declarations reflect the emotional character of national identification and cultural bonds with the "private" homeland as well as strong identification with the Polish minority (this aims at preserving their own identity). The ethnocentric (inherited) identity manifested by the children does not entail depreciation of the culture of the country of residence. Numerous responses of the examined children indicate making endless comparisons of both cultures - the native and the culture of the country of current residence. This takes place in the situation where both the family environment and the school with Polish as the teaching language enhance identification with the values of the native Polish culture. Therefore, the respondents' declarations seem to suggest natural ethnocentrism, resulting from the acquisition of the so-called habitual cultural competences.

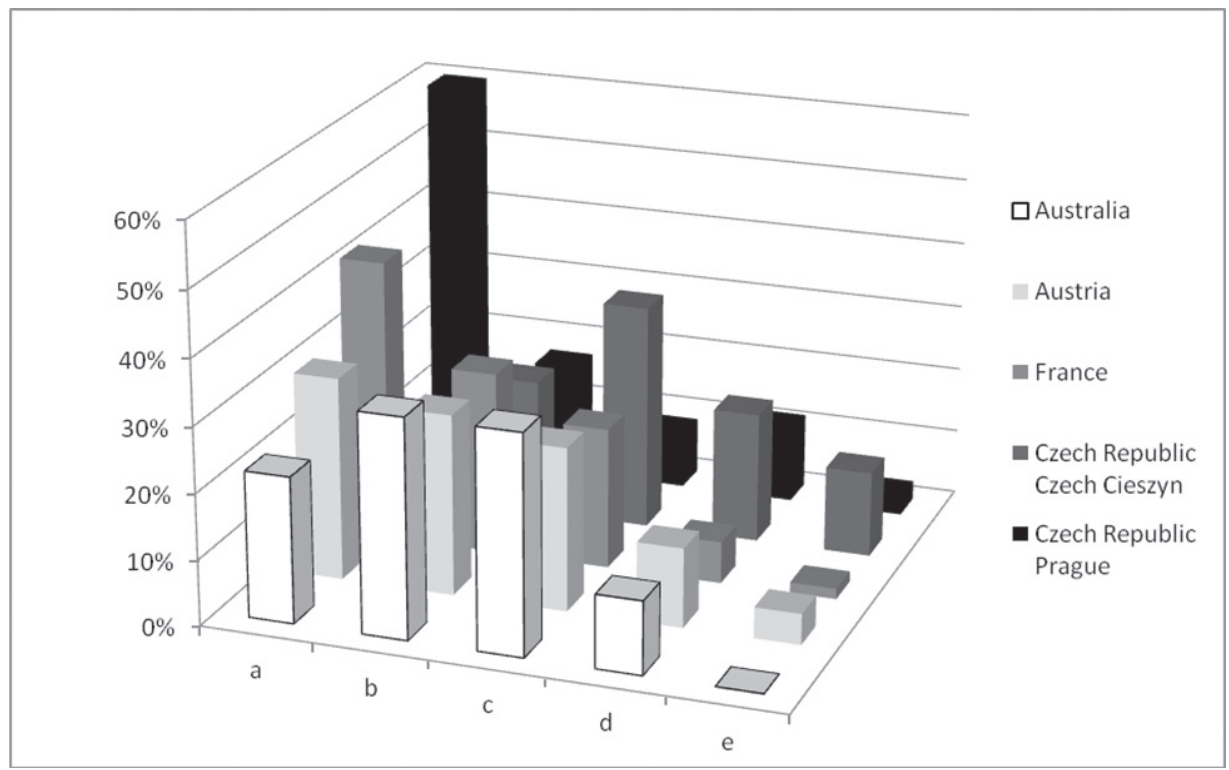

Legend: a - Polish, b - Polish and of country of residence but rather Polish; c - Polish and of country of residence equally; $d$ - Polish and of country of residence but rather of country of residence; $\mathrm{e}-$ of country of residence

Source: own elaboration

Figure 1. The declared feeling of identity of the surveyed learners (percentages). 
33\% of the learners in Australia, 25\% in Austria, 21\% in France and 9\% in Prague define their identity in the category "I feel equally Polish and Australian/ Austrian/French/Czech". The mixed balanced identity declared by them may confirm the feeling of dual national identity and strong identification with two cultures (biculturalism).

The data obtained, owing to the conducted ethnographic observations and interviews, additionally indicate in this subgroup of learners the shaping of two identity types -integrated and dispersed identity. The former combines the elements of the learners' personal system of values with the values of the cultures of groups to which they belong and in the life of which they take part consciously and reflectively. This type of identity is manifested by most of the children born abroad (85\%). Dispersed identity results from the confrontation of inherited identity with the new and changing cultural reality, through which the learners acquire their awareness of belonging to many groups existing "next to" each other. Such identity was declared by significantly fewer respondents (15\%) among those whose stay abroad had lasted $1-5$ years.

The children's communities are also explored in the dimension of homogeneous Australian (11\%), Austrian (17\%), French (8\%) and Czech identity (learners from Prague $-14 \%)$. The learners' identification with the national culture of the majority group indicates the occurring changes in the criterial and correlative identity attributes, which are determined by other factors than family socialization and culturation. Individual talks with the learners also confirm the incidence of the lack of identification both with their own ethnic minority and with the national culture of the country of residence (children living in Prague). Despite the feeling of specific alienation, in this case, the final declarations tend to indicate the latter.

Having compared all the surveyed environments, it can be stated that in Austria the children declare Polish identity significantly more often ${ }^{1}$ than their peers from the Czech Republic - Czech Cieszyn $(\chi 2=18.3 ; \mathrm{p}<0.05 ; \Phi=0.26)$ and that they declare dual identity more frequently than the learners from Prague $\left(\chi^{2}=4.4 ; \mathrm{p}<0.05\right.$; $\Phi=0.15)$. However, they choose the identity of the country of residence significantly less often than the children from Czech Cieszyn $\left(\chi^{2}=9.76 ; p<0.05 ; \Phi=0.19\right)$ and Polish identity than their peers from Prague $(\chi 2=4.23 ; \mathrm{p}<0.05 ; \Phi=0.15)$.

In the French environment, the examined children differ significantly only from the learners from Czech Cieszyn - they more often declare Polish identity $(\chi 2=$ 36.8; $\mathrm{p}<0.05 ; \Phi=0.38)$ and less often declare dual identity $\left(\chi^{2}=5.32 ; \mathrm{p}<0.05\right.$;

1 All the differences between the results in which $\mathrm{p}<0.05$ are statistically significant. 
$\Phi=0.14)$ and the identity of the country of residence $\left(\chi^{2}=24.3 ; \mathrm{p}<0.05 ; \Phi=\right.$ $0.31)$.

Among the Czech respondents, the learners from Prague significantly more often indicate Polish identity $\left(\chi^{2}=22.3 ; \mathrm{p}<0.05 ; \Phi=0.37\right)$ and dual identity $\left(\chi^{2}=8.93 ; \mathrm{p}<0.05 ; \Phi=0.23\right)$, but they choose the identity of the country of residence $\left(\chi^{2}=4.62 ; \mathrm{p}<0.05 ; \Phi=0.17\right)$ less frequently than the children from Czech Cieszyn. Yet, the learners from the Polish-Czech borderland significantly more often declare the identity of the country of residence $(\chi 2=6.58 ; \mathrm{p}<0.05$; $\Phi=0.2)$ and less often - Polish identity $\left(\chi^{2}=6.21 ; \mathrm{p}<0.05 ; \Phi=0.19\right)$ than their peers from Australia.

These statistically confirmed differences indicate a distinct image of national identifications, mostly of the learners from Czech Cieszyn. Their characteristic feature is one-sidedness - local rooting and strong bonds with Zaolzie and Cieszyn Silesia. The specific historical, sociocultural, and economic determinants of the Polish-Czech borderland have been more broadly discussed in the intercultural pedagogical studies conducted in this environment for over 28 years ${ }^{2}$. Comparing these results to the earlier research in this environment (T. Lewowicki, E. Ogrodzka-Mazur, A. Szczurek-Boruta, 2009), currently - fewer children (about $15 \%)$ declare the feeling of dual national identity and they tend to choose the homogeneous Czech nationality (an increase by $12 \%$ ).

The reasons for this situation might be sought in various factors - yet, the observations show that the learners' feeling of dual national identity or their declaring Czech identity is mostly shaped by the education system. They attend schools with Polish as the teaching language but the teachers implement the Czech curricula there. Simultaneous learning of Polish and Czech - and hence close cognitive and emotional contact with both cultures (occurring also in Polish and Czech non-school cultural and educational institutions) causes shrinking of the distance between them and (as regards correlative identity attributes) enables easier acculturation. This process is also occurring in the other investigated environments but does not show such intensity. The children consider themselves Poles, but they also express the feeling of dual national (Polish-Australian, Polish-Austrian, Polish-French) identity. However, more frequently than their peers from Czech

${ }^{2}$ So far, 75 volumes have been published in the series "Edukacja Międzykulturowa /Intercultural Education/", prepared by the Social Team for Research into Borderland Education and Culture and the Department and Chair of General Pedagogy of the Faculty of Ethnology and Education in Cieszyn (University of Silesia), supervised by Tadeusz Lewowicki. 
Cieszyn, they associate their life and educational plans with their present country of residence, where they hope for more chances for "better" life than in Poland.

\section{Parents and teachers}

Contrary to the examined learners, their parents (cf., Figure 2) declare similar intensity of their feeling of identity, which does not differentiate depending on the environment of the native country or country of residence (apart from the parents from Australia and Czech Cieszyn), the age and the length of their stay abroad. All the examined parents living in Austria and the Czech Republic (Prague) and 92\% of the parents in France and 67\% in Australia manifest their feeling of Polish identity and strong identification with the Polish minority group. As in the case of their children, the ethnocentric identity declared by the parents does not mean depreciation of the culture of the country of residence, which is confirmed by numerous responses in the questionnaires and individual talks. The respondents also indicate making comparisons of both cultures and confirm that the regular contact with the Polish school and church (Australia, Austria and France) as well as with other organizations run by the local Polish community enhances their identification with the native Polish culture.

The majority of the examined parents currently living in Australia (Perth) and in big European capital cities (Paris, Prague, Vienna) were born in Poland, where their feeling of national identity was shaped over many years of natural experience of belonging to the family, school, peer or religious community. According to the standpoints of many researchers exploring the issues of identity, this type of identification entails some imprinted permanence and unchangeability, even though it constitutes a dynamic whole. Each change in this area is hardly negotiable and is assessed in ethical and moral categories. Therefore, it should not surprise that the respondents declared the feeling of Polish identity. On the other hand, it is important that parents have a positive attitude to the culture of the country of their present residence and that they are gradually decreasing the cultural distance, which they also notice.

Having compared all the environments, it can be stated that the parents in Austria declare Polish identity significantly more often than the parents from Czech Cieszyn $(\chi 2=20.0 ; \mathrm{p}<0.05 ; \Phi=0.42)$ and Australia $\left(\chi^{2}=12.7 ; \mathrm{p}<0.05\right.$; $\Phi=0.45)$. However, they indicate dual identity significantly less often than the parents from Czech Cieszyn $(\chi 2=20.0 ; \mathrm{p}<0.05 ; \Phi=0.42)$ and Australia $\left(\chi^{2}=12.7\right.$; $\mathrm{p}<0.05$; $\Phi=0.45$ ). Moreover, they indicate the identity of the country of residence 


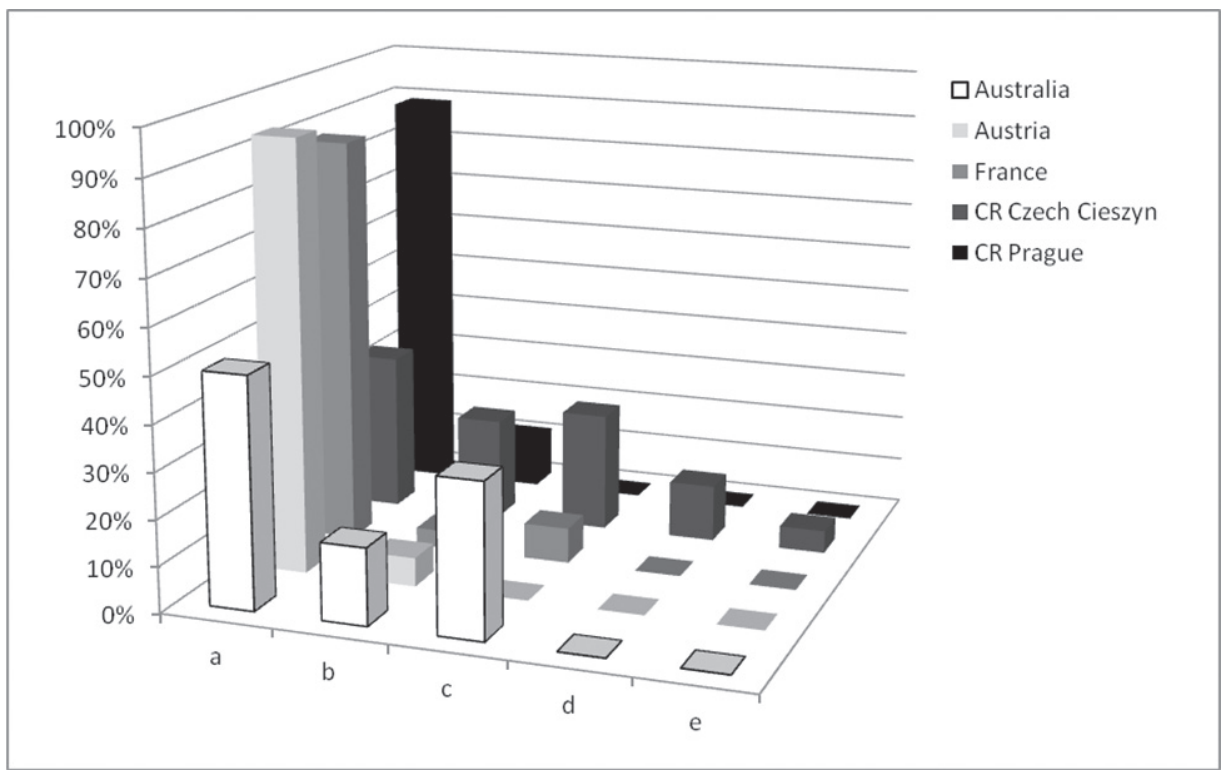

Legend: $\mathrm{a}$ - Polish, b - Polish and of country of residence but rather Polish; c - Polish and of country of residence equally; $d$ - Polish and of country of residence but rather of country of residence; $\mathrm{e}-\mathrm{of}$ country of residence

Source: own elaboration.

Figure 2. The declared feeling of identity of the surveyed parents (percentages)

significantly more often than the parents from Czech Cieszyn $\left(\chi^{2}=6.31 ; \mathrm{p}<0.05\right.$; $\Phi=0.24)$.

In the French environment, the parents declare Polish identity significantly more often than the parents from Australia $\left(\chi^{2}=8.8 ; \mathrm{p}<0.05 ; \Phi=0.3\right)$ and they choose dual identity less often than the Australian parents as well $(\chi 2=8.8$; $\mathrm{p}<0.05 ; \Phi=0.33$ ).

In the Czech environment, the parents from Prague declare Polish identity significantly more often than the parents from Australia $(\chi 2=4.03 ; \mathrm{p}<0.05 ; \Phi=$ $0.32)$ and from Czech Cieszyn $\left(\chi^{2}=6.4 ; \mathrm{p}<0.05 ; \Phi=0.27\right)$. Yet, they indicate less frequently the identity of the country of residence $(\chi 2=8.0 ; \mathrm{p}<0.05 ; \Phi=0.27)$ and dual identity $(\chi 2=4.03 ; \mathrm{p}<0.05 ; \Phi=0.32)$ than the parents from Australia. The parents from Czech Cieszyn declare significantly more often the identity of the country of residence than the parents from Australia $(\chi 2=8.0 ; \mathrm{p}<0.05 ; \Phi=0.27)$.

Similarly to their children, the declarations of the parents from Czech Cieszyn concerning their feeling of identity were aggregated in three groups: $33 \%$ declared 
homogeneous Polish (Silesian, Zaolzie) identity, 26\% balanced Polish and Czech identity and $17 \%$ homogeneous Czech identity. In the Australian environment, two aggregations appeared, which comprised $67 \%$ of declarations of homogeneous Polish identity and $33 \%$ of balanced Polish and Australian identity. The intensity of the parents' national identifications is lower than in the case of these parents' children - yet, this indicates evident changes also in the environment of the parents, who are now entering nationally and/or religiously mixed marriages with growing frequency (Sussex, Zubrzycki, 1985; Smolicz, 2001, pp. 27-41).

As the majority of the parents, the last of the surveyed communities - the teachers working in schools with Polish as the teaching language - declare the feeling of only Polish identity in Austria and the Czech Republic (Prague), Polish identity (50\%) or Polish and that of the country of residence (50\%) to the same extent in Australia, and in Czech Cieszyn - Polish identity (62\%) or Polish and that of the country of residence, but rather Polish (38\%) (cf., Figure 3).

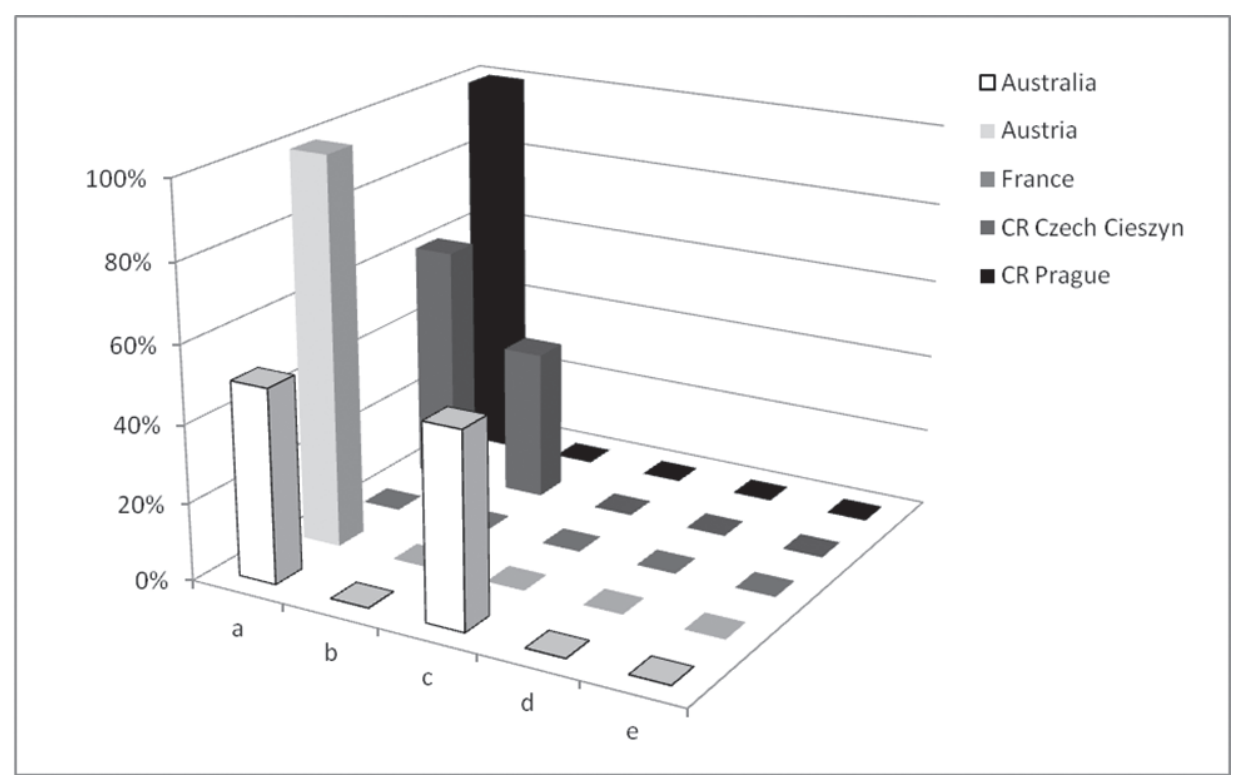

Legend: a - Polish, b - Polish and of country of residence but rather Polish; c - Polish and of country of residence equally; $\mathrm{d}$ - Polish and of country of residence but rather of country of residence; $\mathrm{e}-\mathrm{of}$ country of residence

Source: own elaboration

Figure 3. The declared feeling of identity of the surveyed teachers (percentages) 
Observation of the behaviours and classes conducted by the teachers from the school with Polish as the teaching language in Paris, who did not take part in the questionnaire, as well as their individual statements, might suggest a similar tendency - choosing Polish national identity.

Teachers working in Polish educational institutions abroad constitute a group of professionals from whom, due to the specificity of their jobs, the implementation of many tasks specified in developmental plans of schools are required (Ogrodzka-Mazur, 2016, pp. 54-86). These tasks mostly entail developing learners' feeling of national identity and cultural sensitizing to Others. This results from children's attending majority schools and from parental expectations. Despite the difficulty which these tasks cause, undertaking them in educational practice provides opportunities for shaping authentic intercultural relations in the investigated environments.

\section{Conclusions}

The outlined characteristics of identity behaviours among the communities of schools with Polish as the teaching language in Australia and some European countries makes it possible to formulate a few most important conclusions:

- The surveyed learners manifest different levels of intensity in their feeling of identity and these levels differ depending on the environment of the country of permanent or temporary residence, their age and duration of their stay abroad. The differences point to the currently noticeable tendency to identify the young generation with various communities - of their native country, local, or - more broadly - European or supra-European ones. Constructing children's identity by themselves means drifting apart from the homogeneous dimension towards discovering and conscious choice of enriched, multidimensional identity. As regards the applied culturalization strategies, what seems to be a characteristic feature of $70 \%$ of the examined learners from Austria, France and the Czech Republic (Prague) is the integrative profile, manifested in the positive attitude and willingness to preserve their own cultural heritage, as well as in the openness and active participation in the life of the receiving society. Due to different historical, economic and sociocultural determinants, their peers from Australia and the Czech Republic (Czech Cieszyn) more often feel Poles and Australians/Czechs to the same extent and they favour the ethnic character of the culturalization strategies which they 
choose. Interpreting the obtained research results in the context of the theory of identity behaviours, it should be stated that - from the angle of children's functioning in culturally diversified environments - special significance is to be attributed to the first field, comprising their (also national) identification with a particular territory and social environment. In the sphere of language, belonging to the second field of identity, the learners show behaviours which confirm a need for good command of the native language and its dialects, as well as a need for using the majority language (English, German, French, Czech) in daily social situations. Therefore, the bilingualism/multilingualism they acquire most frequently has the "additive" character and enables high competence in both/all used languages as well as integrative communication. The surveyed children's identity behaviours also refer to the fourth field, associated with the economic condition and living standards of the group, which specify the level of fulfilling their needs. The children's expectations are to a large extent related to the life in the country of residence and/or in other European countries (learners from Prague). As in the case of the children from Czech Cieszyn, they are also associated with life and educational plans fulfilled in Poland.

- The majority of the parents and teachers from schools with Polish as the teaching language in Europe manifest the feeling of Polish identity and strong identification with the Polish minority group. As in the case of the examined children, the ethnocentric identity declared by them does not mean depreciating the culture of the country of residence. This is confirmed by their culturalization strategies, the profile of which is integrative - involving mutually balanced levels of ethnic and national indicators concerning identity, knowledge and use of languages or social contacts. Due to different motives of migration and the longest stay abroad (16-20 years and more), the identity behaviours of the parents and teachers from Australia are characterized by their identification both with the Polish minority group and with the majority group of the country of residence. In reference to Boski's levels of integration, the cultural identity declared by adults and their identity behaviours indicate positive valuing of biculturalism, acquisition of bilingual competences, and in some cases (parents from Australia and Austria) - language and religious syncretism. 


\section{References}

Boski, P. (1995). National identity of Poles in and out of the motherland: implications for European (trans-cultural) integration. Journal for Mental Changes: Perspective of Economic, Political and Social Integration, 2, 143-162.

Lewowicki, T. (2018). Manifestations of permanence and changeability in different spheres of spiritual life - a few generalizations with the Theory of Identity Behaviours in the background. In: T. Lewowicki, E. Ogrodzka-Mazur, B. Chojnacka-Synaszko, U. Klajmon-Lech (eds). Spheres of spiritual life - a study on permanence and changeability of identity behaviours in borderland communities. Munich: LINCOM Academic Publishers, 191-205.

Lewowicki, T., Ogrodzka-Mazur, E., \& Szczurek-Boruta, A. (eds) (2009). Poczucie tożsamości i stosunek młodzieży do wybranych kwestii społecznych - studium z pogranicza polsko-czeskiego [Youth's feeling of identity and attitude toward selected social issues - a study from the Polish-Czech borderland] . Cieszyn - Warszawa - Toruń: Wydział Etnologii i Nauk o Edukacji Uniwersytetu Śląskiego, Wyższa Szkoła Pedagogiczna ZNP w Warszawie, Wydawnictwo Adam Marszałek.

Lewowicki, T., Nikitorowicz, J., \& Szczurek-Boruta, A. (eds) (2010). Szkolnictwo z polskim językiem nauczania w państwach europejskich - stan, problemy i perspektywy [School education with Polish as the teaching language in European countries -condition, problems and prospects]. Białystok - Cieszyn - Warszawa: Uniwersytet w Białymstoku, Wydział Etnologii i Nauk o Edukacji Uniwersytetu Śląskiego, Wyższa Szkoła Pedagogiczna ZNP w Warszawie, Stowarzyszenie Wspierania Edukacji Międzykulturowej.

Nikitorowicz, J. (2009). Edukacja regionalna i międzykulturowa [Regional and intercultural education]. Warszawa: WAiP.

Ogrodzka-Mazur, E. (2016). The specificity of educating young learners in the culturally diversified environment. In: E. Ogrodzka-Mazur, A. Szafrańska-Gajdzica, B. Grabowska, $\&$ \&. Kwadrans. Education of children and youth in culturally diverse environments: experiences - problems - prospects. Munich: LINCOM Academic Publishers, 54-86.

Smolicz J.J. (2001). Globalization and cultural dynamics in a multiethnic state: Australian multiculturalism from an international perspective. Dialogue and Universalism, 11-12, $27-41$.

Sussex, R., \& Zubrzycki, J. (eds) (1985). Polish people and culture in Australia. Canberra: Department of Demography, Institute of Advanced Studies, The Australian National University. 